\title{
Impregnation of Carbonate Rock with Bituminous Compounds. II. Improvement of the Impregnation Material
}

\author{
Farid M. Gumerov1, Mansur I. Farakhov², Vener F. Khayrutdinov², Rashit F. Gabitov', \\ Zufar I. Zaripov' ${ }^{1}$, Ilnar Sh. Khabriyev', Talgat R. Akhmetzyanov ${ }^{1}$ \\ ${ }^{1}$ Federal State Budgetary Educational Institution of Higher Professional Education "Kazan National Research \\ Technological University", Kazan, Russian Federation \\ ${ }^{2}$ Limited Liability Company Engineering-Promotional Center “Inzhekhim”, Kazan, Russian Federation \\ Email: gum@kstu.ru
}

Received 22 October 2015; accepted 8 December 2015; published 11 December 2015

Copyright (C) 2015 by authors and Scientific Research Publishing Inc.

This work is licensed under the Creative Commons Attribution International License (CC BY). http://creativecommons.org/licenses/by/4.0/

(c) (i) Open Access

\section{Abstract}

The steam-thermal method for refinery of highly-viscous oils and the process of propane-butane liquid extraction have been implemented for production of the impregnation material for carbon rock. The process of steam-thermal treatment has been carried out for highly-viscous oil from Ashalchinskoye accumulation with the "steam-oil" ratio changing from 1.1:1 to 1.4:1. The extraction process has been carried out at temperature $T=85^{\circ} \mathrm{C}$ and pressures from 4.5 to $8 \mathrm{MPa}$. Water absorption of carbonate rock has decreased to $0.34 \%$ as a result of SCF-impregnation process.

\section{Keywords}

Highly Viscous Oil, Steam-Thermal Method, Carbonate Rock, Impregnation, Supercritical Fluid (SCF) State

\section{Introduction}

A characteristic feature of modern oil production is the increase of hard-to-extract reserves in the global structure of raw materials. These reserves mainly include heavy and highly viscous oils with a viscosity of $30 \mathrm{mPa} \cdot \mathrm{s}$ or $35 \mathrm{~mm}^{2} \cdot \mathrm{sec}^{-1}$ and above. In industrialized countries, they are considered not as a provision of oil, but as the main base for its development in the upcoming years [1].

The largest accumulations are located in Canada, Venezuela, and USA. It is due to the fact that these countries are among the first that have shown their interest in production and processing of heavy oil feedstock [2]. 
Russia is considered the third country after Canada and Venezuela, in terms of heavy hydrocarbon reserves. According to the Institute of Inorganic Chemistry (RAS), Russian reserves of highly viscous oil are estimated at 6.3 billion [3].

Nowadays, according to experts, the best way of utilizing of heavy crude oil is the processing into lightweight synthetic oil or oil-products, thereby reducing the cost of their transportation. The term "synthetic oil" is commonly understood as lightweight oil with low viscosity, obtained in the conversion process of heavy oil, with the release of heavy residues as a separate phase [4].

Group composition of heavy and extremely highly-viscous oil (EHVO) is characterized by a low content of paraffin hydrocarbons and high content of resins and asphaltenes, which makes these oils a good raw material for road bitumen production, for example [5]. At the same time, the volume of heavy residue after conversion process of EHVO exceeds the demand for road bitumen, and this causes the search for other ways of applying or ways to increase the depth of its processing.

In publication [6] a complex process is suggested for deasphaltizing of heavy oil residue and subsequent impregnation (using a solvent in SCF state) of carbonate rock by deasphaltizate in order to improve the functional characteristics of the latter. As a result of the uniform impregnation, inaccessible for traditional methods, such important characteristic as water absorption has decreased from $3.6 \%$ to $0.54 \%$. However, despite a thorough impregnation of gravel and such a significant decrease in water absorption, some problems have been revealed. In particular, the concentration of deasphaltizate (impregnation material) on the surface of rock, though not much, but is actually higher than the one that takes place in the nucleus of rock granules. One of the ways to solve this problem may appear, among other issues, as the improvement of characteristics of the initial feedstock subjected to deasphaltizing. As part of the study of this opportunity an alternative technology has been discovered for initial feedstock production [5]. That is the steam-thermal method for separating of highly-viscous oil into synthetic oil and a heavy residue for the deasphaltizing process.

\section{Experimental Part}

Extremely highly-viscous oil (EHVO) from Ashalchinskoye accumulation (Republic of Tatarstan, Russian Federation) has been selected as an object of the study. The main drawbacks of this oil include: ultra-low yield of light fractions (gasoline fractions are totally absent and diesel fractions are represented by only 12\%), a high content of asphaltenes, resins and sulfur (Table 1), as well as high viscosity which makes technical and energy problems during the transportation.

An experimental plant has been built for the separation of the oil with a productivity rate of up to 5 kilograms of feedstock per hour. Schematic diagram of the plant is presented in Figure 1.

Feeding of oil from a feedstock reservoir to a feed plate in the top part of a packed column is performed by the corresponding pump. Thus, the pumped oil flows through the feed preheater. At the bottom of the column a superheated steam is fed, produced from distilled water by a superheater.

Inside the column there is an intense distillation of light distillates and gasoil fractions from the heated heavy oil. Vaporized components climb up the column, contacting with hot oil flowing down the nozzle, heat and mass transfer occurs. As a result, residual product accumulates in the bottom of the column and the light part concentrates in the top part of the column. The heavier gasoil fractions condense on the uppermost hollow plate, where

Table 1. Physical and chemical properties of the oil [7].

\begin{tabular}{cc}
\hline Parameter & Value \\
\hline Density at $20^{\circ} \mathrm{C}, \mathrm{kg} \cdot \mathrm{m}^{-3}$ & 965 \\
Viscosity at $20^{\circ} \mathrm{C}, \mathrm{cSt}$ & 3000 \\
Mass fraction of sulfur, \% & 4.5 \\
Mass fraction of resins, \% & 28.0 \\
Mass fraction of asphaltenes, \% & 5.5 \\
Mass fraction of paraffin, \% & 1.4 \\
Mass fraction of nickel, \% & $0.002-0.008$ \\
Mass fraction of vanadium, \% & $0.02-0.03$ \\
\hline
\end{tabular}




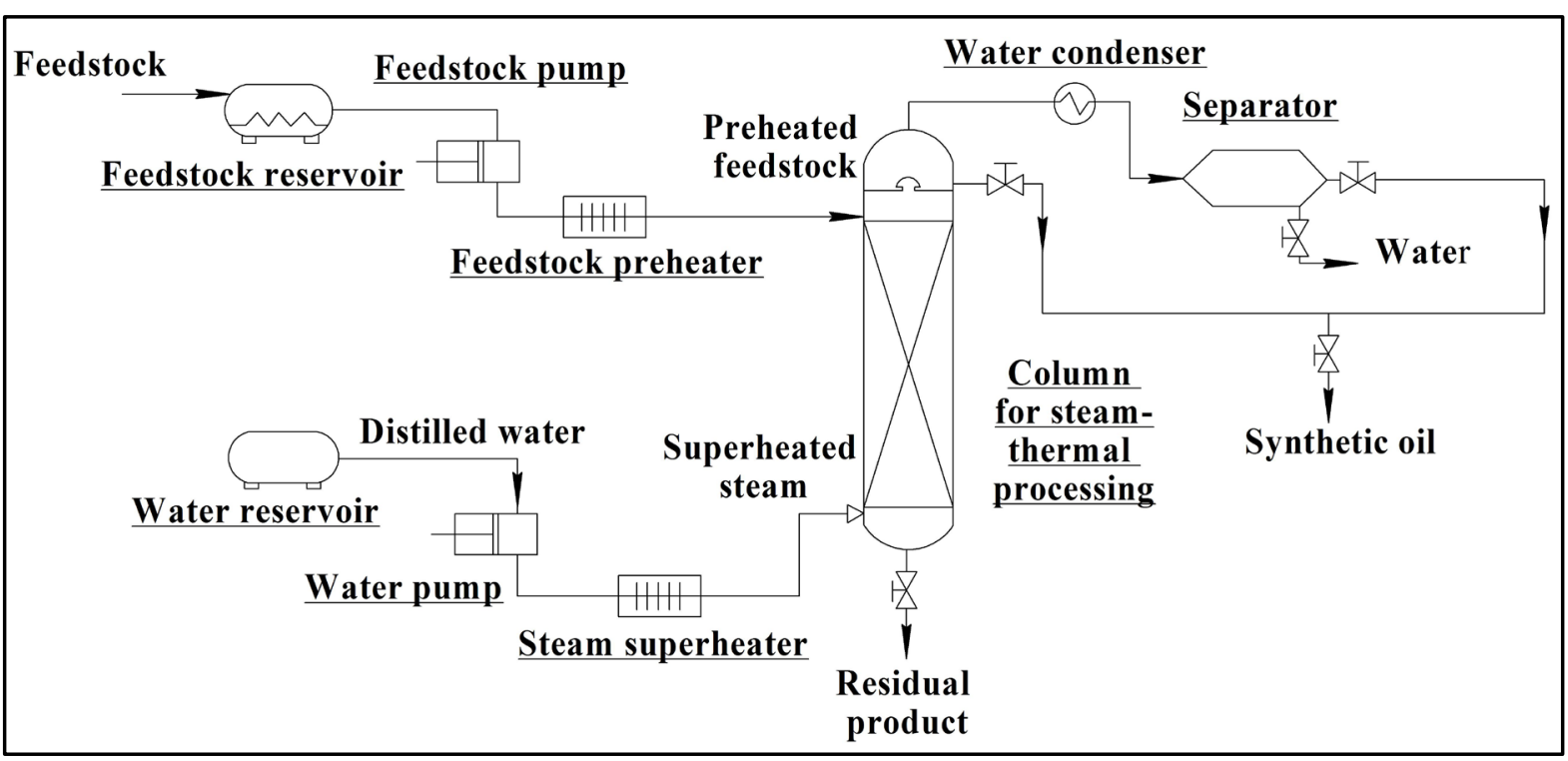

Figure 1. Schematic diagram of the plant for steam-thermal processing of EHVO [5].

collection of these fractions takes place. Side distillation shall be taken in case to facilitate the separation of water from the upper product. The lighter distillate fractions together with steam pass through a water condenser and are collected in a receiving vessel, where due to the density difference the water is separated from the organic fraction. The resulting side product and upper product are mixed to form "synthetic" oil. The residual product may perform as raw material for producing deasphaltizate in the frames of the integrated impregnation process of carbonated gravel, and also as road bitumen.

A detailed description of the complex process for deasphaltizing of heavy oil residue and subsequent SCFimpregnation of rock by deasphaltizate is given in [6].

Propane-butane mixture has been applied as the extractant liquid (deasphaltizing step), and the supercritical fluid solvent (SCF-impregnation step) [8], comprising of $75 \%$ of propane and $25 \%$ of butane. Critical parameters of the propane-butane mixture according to [9] [10] are characterized by the following values: $\mathrm{T}_{\mathrm{cr}}=386 \mathrm{~K}$, $\mathrm{P}_{\mathrm{cr}}=4.31 \mathrm{MPa}$.

\section{Results and Discussion}

The set of experiments has been carried out concerning the steam-thermal influence on the oil from Ashalchinskoye accumulation with a subsequent analysis of the heavy residues obtained. During the investigation of the oil separation process by steam-thermal method the temperature in the mixer and the ratio of "steam/feedstock" have been varied. Parameters of the experiments carried out are presented in Table 2.

At the end of each experiment, the material balance of the process has been considered and masses of the obtained light fractions and heavy residues have been measured separately (Table 3).

Synthetic oil (SO) has been subjected to atmospheric and vacuum distillation and its characteristics have been analyzed (Table 3, Figure 2).

The heavy residue samples have been subjected for compliance test with road bitumen requirements according to GOST 22245-90 [11]. The results obtained are shown in Table 4.

Table 3 shows that the residues correspond to basic indicators of quality required for road bitumenbrands BND 40/60, BND 60/90, BND 90/130.Thus, there is a clear pattern: the greater the yield of the synthetic oil, the smaller the penetration value of the produced bitumen.

Because of its properties, heavy residue is a good feedstock for road bitumen. However its volumes exceed the demand for road bitumen. To increase the depth of the feedstock processing the liquid-extraction process of propane-butane deasphaltizing is proposed allowing the producing of deasphaltizate for subsequent implementation as the impregnating material for carbonated gravel.

Conditions for the deasphaltizing process are presented in Table 5 with a heavy residue obtained under 
Table 2. Conditions of the experiments and the yields of the products.

\begin{tabular}{|c|c|c|c|c|}
\hline \multirow{2}{*}{ Parameter } & \multicolumn{4}{|c|}{ Value } \\
\hline & Exp. No.1 & Exp. No.2 & Exp. No.3 & Exp. No.4 \\
\hline $\mathrm{t}_{\text {preheater, }}{ }^{\circ} \mathrm{C}$ & 300 & 290 & 300 & 300 \\
\hline $\mathrm{t}_{\text {mixer }},{ }^{\circ} \mathrm{C}$ & 597 & 523 & 516 & 527 \\
\hline $\mathrm{t}_{\text {steam }},{ }^{\circ} \mathrm{C}$ & 650 & 620 & 610 & 630 \\
\hline $\mathrm{t}_{\text {column-top }}{ }^{\circ} \mathrm{C}$ & 147 & 113 & 108 & 121 \\
\hline $\mathrm{t}_{\text {column-bottom, }},{ }^{\circ} \mathrm{C}$ & 209 & 186 & 114 & 109 \\
\hline $\mathrm{t}_{\mathrm{bit}},{ }^{\circ} \mathrm{C}$ & 341 & 325 & 301 & 331 \\
\hline "Steam/feedstock" mass ratio & 1.4:1 & 1.1:1 & $1.1: 1$ & $1.2: 1$ \\
\hline Synthetic oil, \% mass & 63 & 60 & 61 & 61 \\
\hline Heavy residue, $\%$ mass & 37 & 40 & 39 & 39 \\
\hline
\end{tabular}

Table 3. Parameters of the feedstock and synthetic oil samples.

\begin{tabular}{|c|c|c|c|c|c|c|}
\hline No. & Parameter & Initial oil & $\begin{array}{l}\text { SO } \\
\text { exp. } 1\end{array}$ & $\begin{array}{l}\text { SO } \\
\text { exp. } 2\end{array}$ & $\begin{array}{l}\text { SO } \\
\text { exp. } 3\end{array}$ & $\begin{array}{l}\text { SO } \\
\text { exp. } 4\end{array}$ \\
\hline 1 & Content of sulfur, \% mass & 4.37 & - & 2.84 & 3.24 & 3.77 \\
\hline 2 & Density at $20^{\circ} \mathrm{C}, \mathrm{kg} \cdot \mathrm{m}^{-3}$ & 963 & 898 & 892 & 935 & 919 \\
\hline 3 & $\begin{array}{l}\text { Fractions yield, } \% \text { mass } \\
\text { up to } 200^{\circ} \mathrm{C} \\
\text { up to } 300^{\circ} \mathrm{C} \\
\text { up to } 350^{\circ} \mathrm{C}\end{array}$ & $\begin{array}{c}4 \\
12 \\
20\end{array}$ & $\begin{array}{c}5 \\
29 \\
44\end{array}$ & $\begin{array}{c}8 \\
37 \\
52\end{array}$ & - & $\begin{array}{c}4 \\
18 \\
24\end{array}$ \\
\hline 4 & $\begin{array}{c}\text { Kinematic viscosity at } 20^{\circ} \mathrm{C} \text {, } \\
\text { CSt }\left(\mathrm{mm}^{2} \cdot \mathrm{sec}^{-1}\right)\end{array}$ & 2268 & - & 16.4 & 39.9 & 131 \\
\hline
\end{tabular}

Table 4. The results of compliance tests of the heavy residue samples.

\begin{tabular}{|c|c|c|c|c|c|}
\hline \multirow{3}{*}{ Sample No. } & \multicolumn{5}{|c|}{ Indicators } \\
\hline & \multicolumn{2}{|c|}{ Penetration, points } & \multirow{2}{*}{$\mathrm{t}_{\mathrm{xr}} \cdot{ }^{\circ} \mathrm{C}$} & \multirow{2}{*}{ Ductility at $0^{\circ} \mathrm{C}, \mathrm{cm}$} & \multirow{2}{*}{${ }^{\circ} \mathrm{C}$} \\
\hline & $25^{\circ} \mathrm{C}$ & $0^{\circ} \mathrm{C}$ & & & \\
\hline 1 & 40 & 7 & -12 & 2.4 & - \\
\hline 2 & 109 & 22 & -15 & 29 & - \\
\hline 3 & 114 & 29 & -18 & 23.5 & 44 \\
\hline 4 & 63 & - & -12 & 4 & 48 \\
\hline
\end{tabular}

Table 5. Conditions of the deasphaltizing process.

\begin{tabular}{ccccc}
\hline $\begin{array}{c}\text { No. of the } \\
\text { experiment }\end{array}$ & $\mathrm{t},{ }^{\circ} \mathrm{C}$ & $\mathrm{P}, \mathrm{MPa}$ & "Extractant/heavy residue” mass ratio & Yield of deasphaltizate, \% \\
\hline 1 & 85 & 4.5 & $1.5: 1$ & 68 \\
2 & 85 & 4.5 & $2: 1$ & 55 \\
3 & 85 & 6 & $1.5: 1$ & 65 \\
4 & 85 & 8 & $1: 1$ & 54 \\
\hline
\end{tabular}


steam-thermal method as a feedstock (exp. No.2 in Table 2).

Condition No.1 (Table 5) of the extraction process corresponds to maximum yield of deasphaltizate. According to [12] with the increase of deasphaltizate yield, the content of resins, sulfur, and metals in its structure increases, moreover sulfur and metals are concentrated preferably in asphaltenes.

The impregnation of carbonate rock with the produced deasphaltizate has been carried out under supercritical conditions of propane-butane mixture, namely at a pressure of $7 \mathrm{MPa}$ and temperature of $140^{\circ} \mathrm{C}$.

In order to identify qualitative indicators of the impregnation process the structure of the impregnated rock samples has been studied, for which the corresponding thin sections has been prepared (Figure 3).

As it seen in Figure 3, the voids have rounded and angular shapes. Their dimensions vary from $0.1 \mathrm{~mm}$ to 0.2 $\mathrm{mm}$. The walls of the voids are covered with a film of oil, less often voids are filled with the oil. Rock impregnated with the heavy residue obtained under the steam-thermal method (Figure 3(b)), has darker shading. In this case $50 \%$ of lumpy formations are impregnated or at least have oil border, as opposed to $30 \%$, characteristic to the sample (Figure 3(a)) prepared using deasphaltizate with other origin. Fragments provided by crystalline calcite, remained unchanged. Oil-product gets into weakened areas of the rock.

Combination of steam-thermal treatment process of EHVO and deasphaltizing of heavy oil residues with producing of synthetic oil, unoxidized road bitumen and carbonate rocks impregnated by deasphaltizate as a marketable production, seems pretty promising.

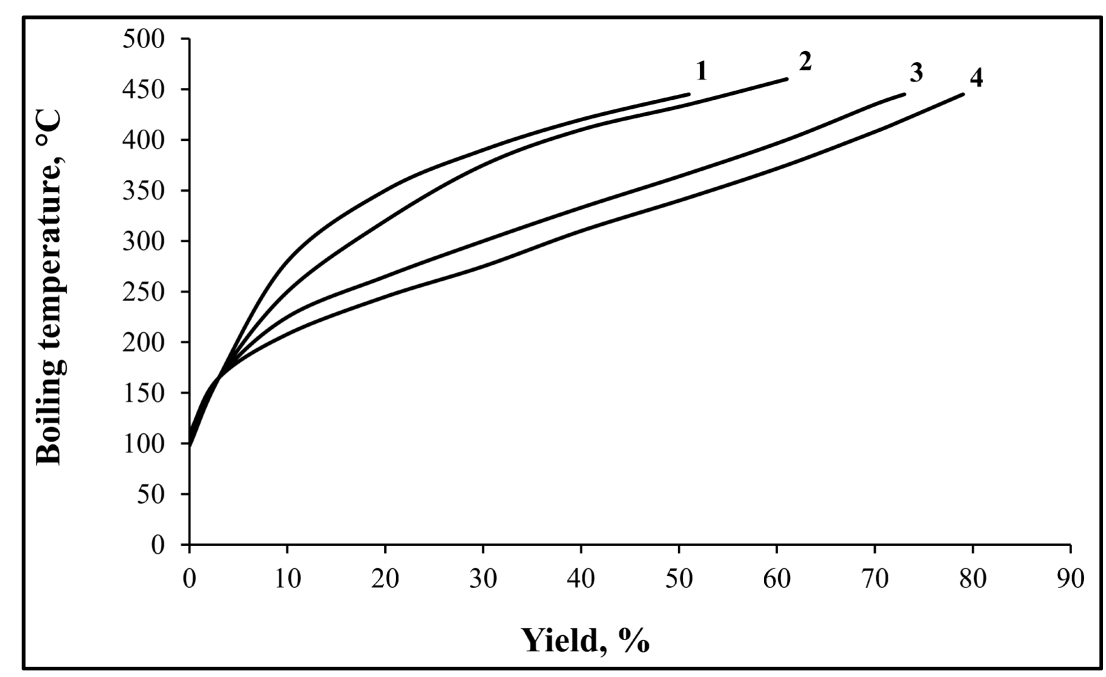

Figure 2. The curves of atmospheric-vacuum distillation: 1-initial oil; 2-synthetic oil (exp. No.4); 3—synthetic oil (exp. No.1); 4—synthetic oil (exp. No.2).

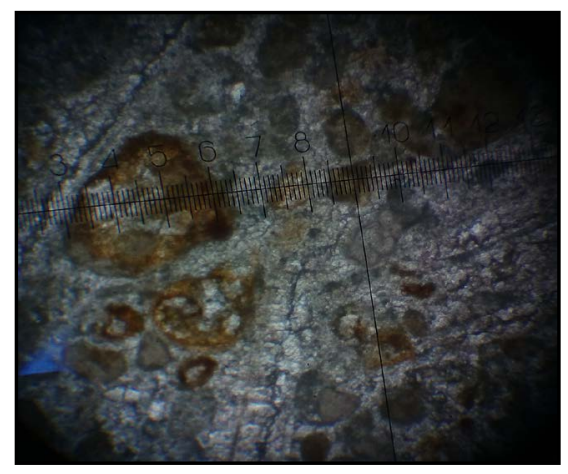

(a)

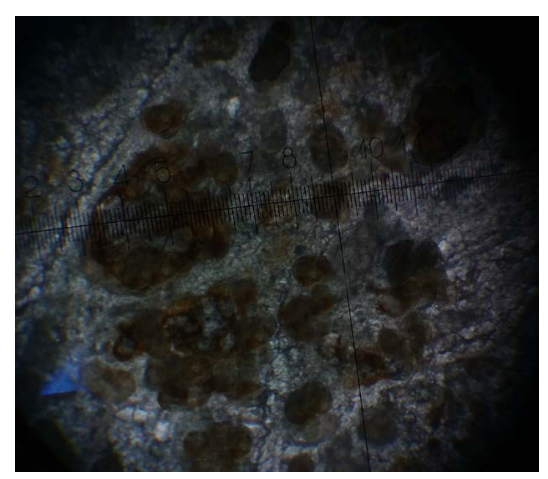

(b)

Figure 3. The photographs of cross-section of the rock samples. (a) Impregnated with the use of deasphaltizate, produced without steam-thermal treatment [6]; (b) Impregnated with the heavy residue, produced under the steam-thermal method for the treatment of highly viscous oil. 


\section{Conclusions}

The patterns affecting the yield of the products are found out, such as: physical and chemical characteristics of the feedstock; process parameters of the steam-thermal treatment and propane-butane extractive deasphaltizing.

An effective technology is developed for impregnating of carbonate rock with oil residues, based on the use of SCF-impregnation process with propane-butane as a solvent. Thorough end-to-end impregnation of rock samples has been achieved.

The implementation of the integrated approach in the processing of highly-viscous oils from Ashalchinskoye accumulation allows increasing of the refining depth and producing of:

- synthetic oil (up to $60 \%$ in terms of initial feedstock);

- raw material for road bitumen;

- deasphaltizate (up to $68 \%$ in terms of heavy oil residue);

- carbonate rock with water absorption coefficient of less than $0.34 \%$.

The proposed technologies have the novelty for a patent [13].

\section{Acknowledgements}

The research has been carried out in Kazan National Research Technological University with the financial support of government represented by the Ministry of Education and Science of Russian Federation. Agreement No.14.574.21.0085.Project's unique identifier RFMEFI57414X0085.

\section{References}

[1] Antoniadi, D.G., Valuyskiy, A.A. and Garushev, A.R. (1999) Methods for Increasing of Oil Recovery in the World Oil Recovery. Oil Industry, 1, 16-23.

[2] Kemalov, A.F., Ganieva, T.F. and Diyarov, I.N. (2007) Study on Natural Bitumen from Nagornoye Accumulation (JSC “Troitskneft”) in Terms to Determine Possibilities of Refinery. PetroleumRefinery and Petrochemistry, 2, $29-32$.

[3] Saghin, V.V., Seldinas, I. and Saghin V.B. (2008) Hard-to-Extract Reserves and “Heavy Oils” of Russia. Successes in Chemistry and Chemical Technology, 12, 56-58.

[4] Kurochkin, A.K. and Toptigin, S.P. (2012) Syntheric Oil. Residue Processing Technology for Russian Heavy Oils. Oil and Gas Refinery, 1, 92-105.

[5] Farakhov, M.I., Fakhrutdinov, R.Z., Khayrutdinov, V.F., Kirichenko, S.M. and Galiullin, E.F. (2014) Investigation of the Heavy Oil Refining Process by the Steam-Thermal Method. Petroleum Refinery and Petrochemistry, 5, 17-19.

[6] Gumerov, F.M., Farakhov, M.I., Khayrutdinov, V.F., Gabitov, F.R., Zaripov, Z.I., Khabriyev, I.Sh. and Akhmetzyanov, T.R. (2014) Impregnation of Crushed Stone with Bituminous Compounds Using Propane/Butane Impregnation Process Carried out in Supercritical Fluid Conditions. American Journal of Analytical Chemistry, 5, 945-956. http://dx.doi.org/10.4236/ajac.2014.514102

[7] Kurochkin, A.K. and Khazeyev, R.R. (2015) Experimental Search of a Promising Technology for Deep Refining of Extremely High-Viscous Oil from Ashal'chninskoe Accumulation. Field, Oil and Gas, 2, 52-71.

[8] Government Standard (GOST) 20448-90. Liquefied Hydrocarbon Gases Fuel for Domestic Consumption.

[9] Kay, W.B. (1970) Vapor-Liquid Equilibrium Relations of Binary Systems. The Propane-n-Alkane Systems. n-Butane and n-Pentane. Journal of Chemical and Engineering Data, 15, 46-52. http://dx.doi.org/10.1021/je60044a026

[10] Beránek, P. and Wichterle, I. (1981) Vapor-Liquid Equilibria in the Propane-n-Butane System at High Pressures. Fluid Phase Equilibria, 6, 279-282. http://dx.doi.org/10.1016/0378-3812(81)85010-8

[11] Government Standard (GOST) 22245-90. Oil and Road Bitumen.

[12] Sultans, F.M. and Khairutdinov, I.R. (2001) Modern Processes of Propane and Propane-Butane Deasphaltizing. Refining and Petrochemicals: Coll. Nauchn. Works IPNHP AN RB, 51-56.

[13] Patent No. 2552286. 